\title{
A skin rash with multiple pulmonary nodules
}

A 37-year-old man presented with a 2-week history of fever and thoracic pain. On physical examination, he presented a nonpruritic skin rash $(0.2-1-\mathrm{cm}$ nontender pink papules) on the trunk (figure 1a), upper extremities, face and soles of the feet, which had developed about 2 months previously. He also had multiple palpable and painful lymph nodes. Additional history revealed that the patient had homosexual contact 3 months before the skin rash developed; a painless genital ulcer developed and then disappeared spontaneously.

Routine blood test results were normal. Rapid plasma reagin and Venereal Disease Research Laboratory test results were positive. Computed tomography (CT) revealed multiple ill-defined pulmonary nodules, mostly in the lower lobes of the lungs (figure $1 \mathrm{~b}$ and $\mathrm{c}$ ). An open lung biopsy demonstrated a peribronchovascular infiltrate and alveolar spaces filled by plasmocytes and histiocytes, without necrosis. Biopsy of a skin lesion showed the same pattern. The patient's history and clinical, laboratory and histopathological findings were compatible with secondary syphilis. The patient was treated with penicillin. 8 weeks after treatment, complete regression of the skin lesions was observed and CT findings were normal.

The prevalence of syphilis has recently increased worldwide [1]. However, pulmonary involvement in secondary syphilis is extremely rare $[2,3]$. To our knowledge, only seven cases of secondary syphilis with pulmonary involvement including CT findings have been published in the English-language literature. All of these cases presented with multiple pulmonary nodules. The association of pulmonary nodules with the characteristic skin lesions may aid diagnosis and the early institution of treatment.
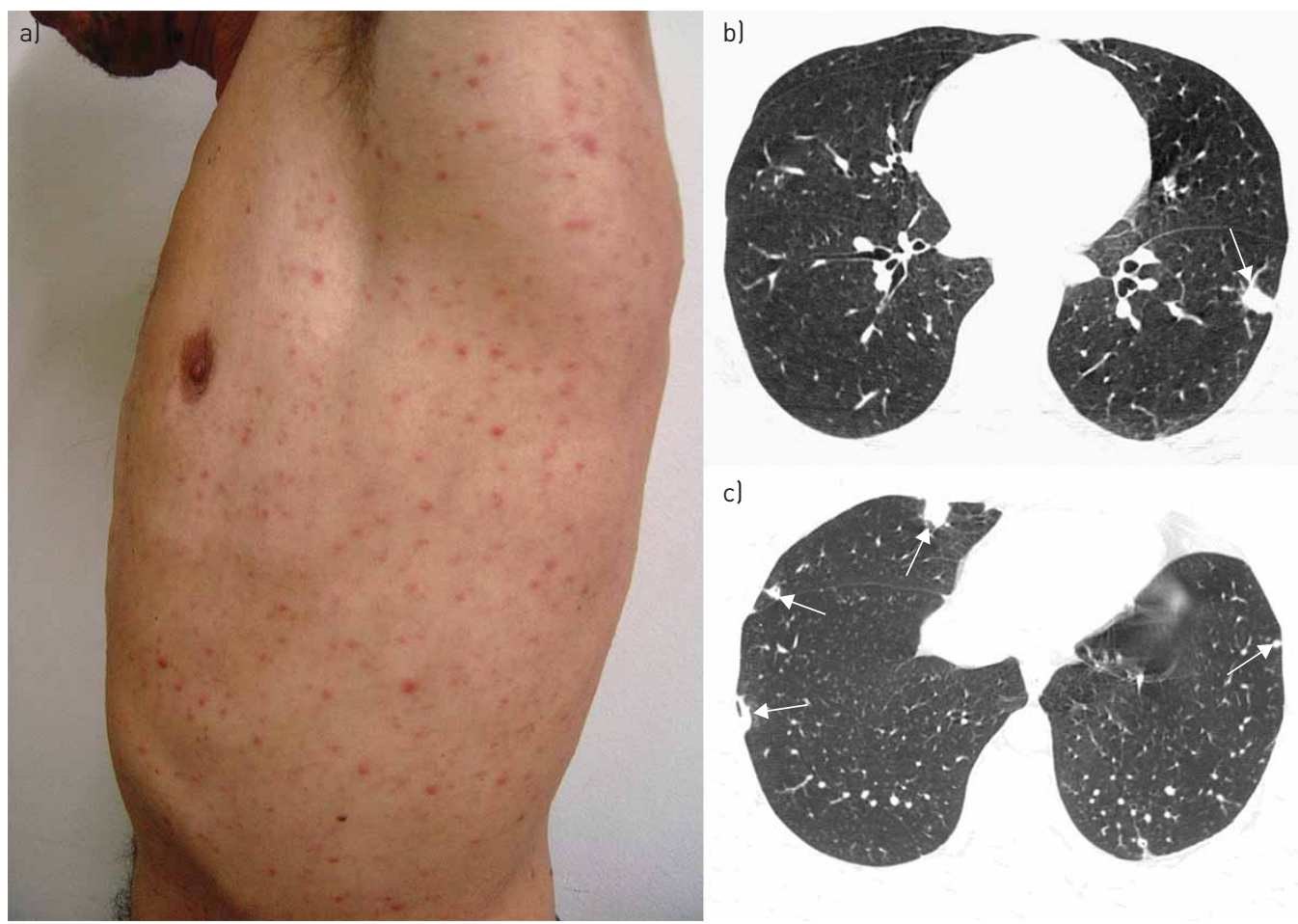

FIGURE 1 a) Photography showing skin rash on the trunk. b and c) Chest computed tomography images obtained at the level of the lower lobes showing multiple small, ill-defined nodules (arrows). 
@ERSpublications

A case of pulmonary involvement in secondary syphilis http://ow.ly/TokOQ

Arthur Soares Souza $\mathrm{Jr}^{1}$, Antonio Soares Souza ${ }^{1}$, Gláucia Zanetti ${ }^{2}$ and Edson Marchiori ${ }^{2}$

${ }^{1}$ Dept of Radiology, Medical School of Rio Preto and Ultra X, São José do Rio Preto, Brazil. ${ }^{2}$ Dept of Radiology, Federal University of Rio de Janeiro, Rio de Janeiro, Brazil.

Correspondence: Edson Marchiori, Rua Thomaz Cameron 438, Valparaiso, CEP 25685.120, Petrópolis, Rio de Janeiro, Brazil. E-mail: edmarchiori@gmail.com

Received: Feb 182015 | Accepted: March 112015

Conflict of interest: None declared.

Provenance: Submitted article, peer reviewed.

\section{References}

1 Cohen SE, Klausner JD, Engelman J, et al. Syphilis in the modern era: an update for physicians. Infect Dis Clin North Am 2013; 27: 705-722.

2 Kim SI, Lee JH, Lee ES, et al. A case of secondary syphilis presenting as multiple pulmonary nodules. Korean J Intern Med 2013; 28: 231-235.

3 Alrajab S, Payne K, Areno J, et al. A 40-year-old man with a nodular lung disease and skin rash. Chest 2012; 141: $1611-1617$.

Eur Respir Rev 2015; 24: 682-683 ｜ＤOI: 10.1183/16000617.00001815 ｜ Copyright CERS 2015 ERR articles are open access and distributed under the terms of the Creative Commons Attribution Non-Commercial Licence 4.0. 